\title{
Fat - A Taxing Matter
}

\author{
Karen Campisano \& Duncan Stewart ${ }^{i}$
}

With increasing rates of obesity and associated obesity related diseases, much attention has been drawn to the latest obesity epidemic, with a variety of solutions proffered. There is a growing amount of evidence relating high intake of trans fats to obesity and coronary heart disease. It has been estimated that "obesity and its associated illnesses cost Australian society and governments a total of $\$ 21$ billion in 2005". (Australian Bureau of Statistics, 2008)

Whilst rates of obesity in upper and middle classes is slowing down, obesity and diabetes rates in the lower socio-economic bracket of society (see Table 1) continue to climb at alarming rates (Australian Bureau of Statistics, 2008).

TABLE 1:SOCIO-ECONOMIC CHARACTERISTICS OF ADULTS AND BMI(a)(b) - 2004-05 BMI category

Normal Overweight Obese Total(c)

Born overseas

Arrived before $1996 \%$

Arrived 1996-2005 \%

Highest non-school qualification

Degree/diploma or higher \% qualification

Other qualification $\quad \%$

No non-school \%

qualification

Household income(d)

Low income

Middle income

$\%$

\%

51.9

33.8

15.0

10.5

100.0

32.3

49.4

34.8

12.9

100.0

41.9

36.9

19.3

100.0

41.3

35.5

20.4

100.0

43.3

32.3

20.6

100.0

44.0

35.7

17.3

100.0 


$\begin{array}{ccrrrr}\text { High income } & \% & 45.8 & 37.6 & 14.9 & 100.0 \\ \text { Index of disadvantage(e) } & & & & & \\ \text { First quintile } & \% & 40.2 & 34.4 & 22.2 & 100.0 \\ \text { Fifth quintile } & \% & 49.8 & 34.6 & 12.8 & 100.0 \\ \text { All persons aged 18 years and over } \% & 44.1 & 35.4 & 17.9 & 100.0 \\ \text { All persons aged 18 years and over '000 } & 6037.0 & 4888.0 & 2478.0 & 13760.6\end{array}$

(a) Sub-populations age standardised to estimated resident population at 30 June 2001.

(b) Based on self-reported height and weight.

(c) Includes persons whose BMI was underweight and excludes persons whose BMI was not stated or not known.

(d) Gross weekly equalised household income. Low income households are in the lowest quintile, middle income in the third quintile and high income in the highest quintile of household income.

(e) The first quintile contains areas with the greatest relative disadvantage and the fifth quintile contains those areas with the lowest relative disadvantage.

Source: Australian Bureau of Statistics, 2008

Much of the blame has been placed on the fast/processed food industry with its use of high quantities of trans fat. Fast food is particularly popular with lower socioeconomic sections of the community due to its low cost and availability (it is an inferior good with negative income elasticity as depicted in Figure 2). According to Longnecker (1997), “about $80 \%$ - 90\% of dietary trans fatty acids come from partially hydrogenated vegetable oils and the rest from natural products such as milk. Margarine, fried food and baked foods are the major sources of partially hydrogenated vegetable oil in the diet".

As rates of obesity and related illnesses climb, so too does the burden on the economy. The cost of treating the obese is currently paid for to a greater extent by the people least likely to need treatment for obesity and related illnesses (the more affluent of society) via progressive income taxes, thus indicating a market failure stemming from the fast food industry whereby unhealthy foods high in trans fats are supplied to maximize profits of suppliers at the cost of society as a whole. 


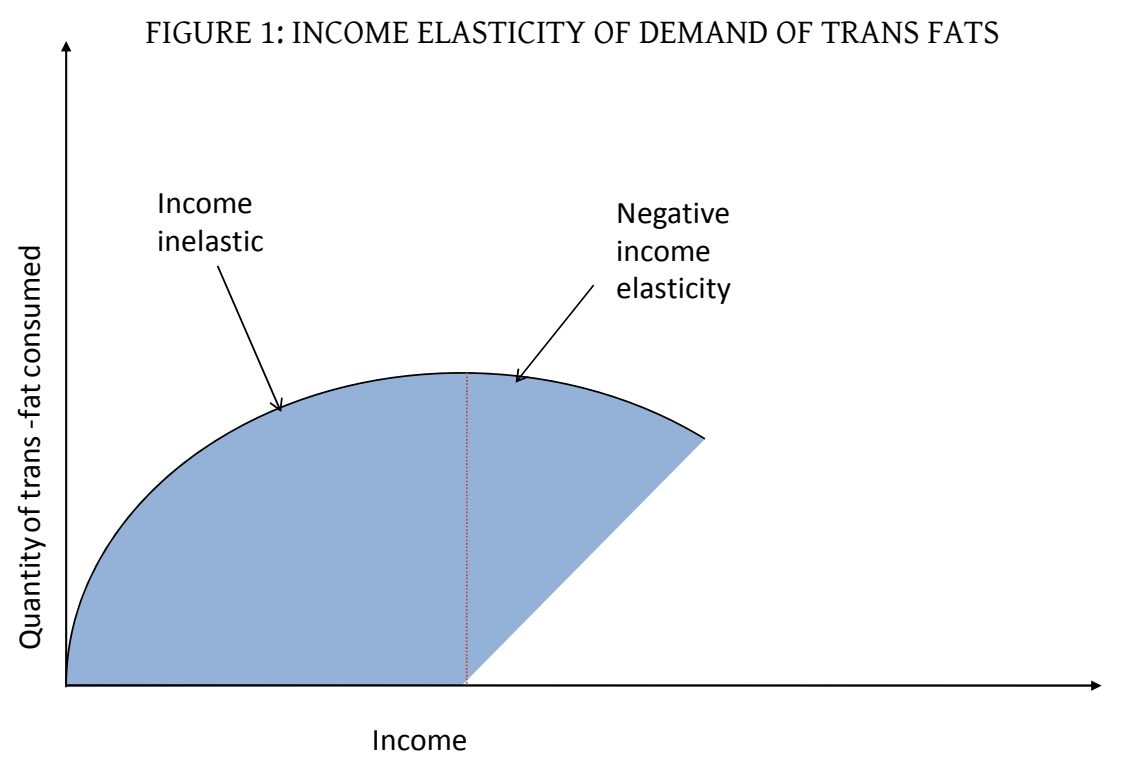

Put simply, to the extent that public health care is being financed by progressive taxes and obesity and its related illnesses predominantly tend to afflict lower socioeconomic groups, obesity can be interpreted as a negative externality imposed by these lower socio economic groups on society. Public health care exacerbates the issue as it implicitly encourages the consumption of unhealthy foods through partly insuring the risk of consuming unhealthy food - a moral hazard problem. As supply of public health care is somewhat limited due to lack of health care professionals, this public service becomes a rival service, such that those with the greater need are treated first. Therefore those who are paying more for the service may not have 
access if the service is consumed by significant numbers of obese patients with higher priority cases.

Further, it has been noted that obese people are exacerbating both the food and fuel crisis due to the consumption of extra food energy (increased number of calories compared to healthy weight people) and having greater reliance on transport, particularly cars (Maley, 2008), contributing to both agflation (the increase in the price of food resulting from increased consumption) and global warming.

A plan to tackle this epidemic thus needs to be implemented rapidly, with the aim of increasing the health and overall benefits to the population at large. It therefore comes as no surprise that one solution, and one of great debate, is the introduction of a "fat tax", with the contentious alternative of a total ban on trans fats.

A number of cities such as New York and soon, Chicago have banned trans fats in restaurants while Denmark has banned trans fat almost outright; limiting trans fat bound for human consumption to $2 \%$ (The New Yorker, 2008).

Imposing a ban on trans fats will reduce consumption if the penalty is great enough (see Figure 2), thus increasing the total cost of trans fats through increasing the unofficial cost, however it is likely to result in vast consumer backlash, with the public demanding it be their right to select what they consume in terms of food. Many such arguments have been seen from parents in relation to strict prohibition rules enforced in their children's schools as seen in England where school-prepared lunches have seen a dramatic drop in orders due to schools cutting out unhealthy options from their menus (The Guardian, 2006). New York City's ban on trans fats in foods prepared in restaurants etc. has also faced some resistance with much of the city's restaurant and food preparation industry concerned with the sourcing of alternatives that do not taste as good and the anxiety over the possibility of being 
forced to pay fines "for inadvertently" using trans fats in food (The New Yorker, 2006).

FIGURE 2: MARKET IMPLCATIONS OF BANNING TRANS FATS

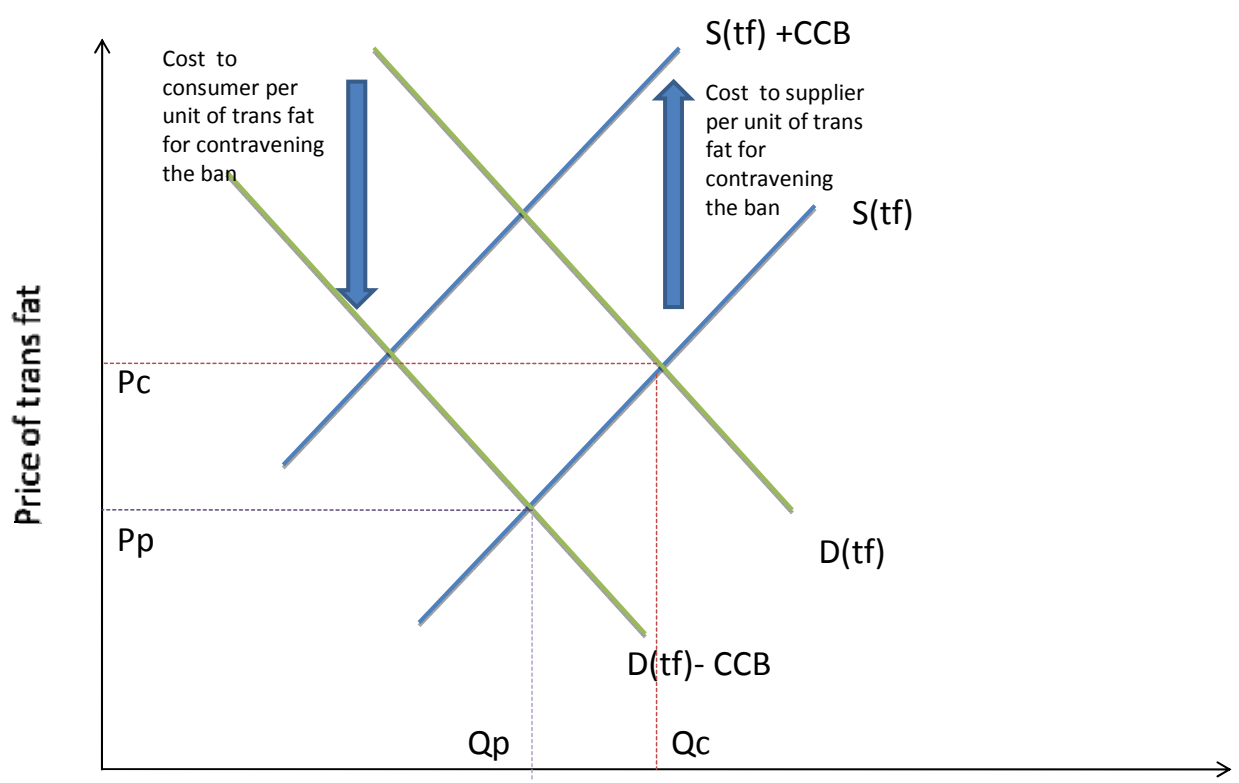

Quantity of trans fats

The demand curve for trans fats is denoted $D(t f)$, the supply curve $S(t f)$. Prior to implementation of the ban, the quantity consumed is Qc at a price of Pc. Post implementation of the ban, the cost of contravening the ban (CCB) is added to the supply cost if imposed on the supplier, and removed from the demand cost if imposed on the consumer. If both supply and consumption of trans fats are banned, the quantity consumed decreases post tax to $\mathrm{Qp}$ at a price of Pp

More fundamentally, a ban placed on trans fats alone may not solve the issue of obesity and its related illnesses since a direct substitute to it exists - saturated fat with a positive cross-elasticity. Saturated fats are more common than trans fats as these fats occur in greater proportions than trans fats. Saturated fats have also been 
linked to obesity, coronary and heart-disease. A total ban covering both trans and saturated fats such as that for trans fats in New York City and Denmark would not be viable as most foods contain naturally occurring saturated fats in some quantities (see Table 2); such a ban would therefore eliminate a significant section of foods from the market.

TABLE 2: SATURATED FAT TYPES IN FOODS

$\begin{array}{lllll}\text { Food } & \text { Lauric Acid } & \text { Myristic Acid } & \text { Palmitic Acid } & \text { Stearic Acid } \\ \text { Coconut Oil } & 47 \% & 18 \% & 9 \% & 3 \% \\ \text { Butter } & 3 \% & 11 \% & 29 \% & 13 \% \\ \text { Ground Beef } & 0 \% & 4 \% & 26 \% & 15 \% \\ \text { Dark Chocolate } & 0 \% & 0 \% & 34 \% & 43 \% \\ \text { Salmon } & 0 \% & 1 \% & 29 \% & 3 \% \\ \text { Eggs } & 0 \% & 0 \% & 27 \% & 10 \% \\ \text { Cashews } & 0 \% & 0 \% & 11 \% & 4 \%\end{array}$

Source: U.S. Department of Agriculture, Agricultural Research Service, (2007)

An alternative to banning fats outright is implementing a tax which enables consumer choice. A tax on trans-fats alone, which would likely be largely borne by the consumer as producer elasticity is great due to readily available substitutes, would decrease trans fat consumption (see Figure 3) but lead to an increase in the consumption of its direct substitutes, namely saturated fat.

Therefore a tax on the total of trans fats and saturated fats would need to be considered, for example, more than $30 \%$ of total trans and saturated fats as calories per 100 grams of food may be taxed - a MacDonald's Big Mac has over $40 \%$ total calories as saturated or trans fat (MacDonald's Nutrition spreadsheet, 2007), increasing the appeal of healthier alternatives. 
FIGURE 3: MARKET IMPLCATIONS OF TAXING TRANS FATS

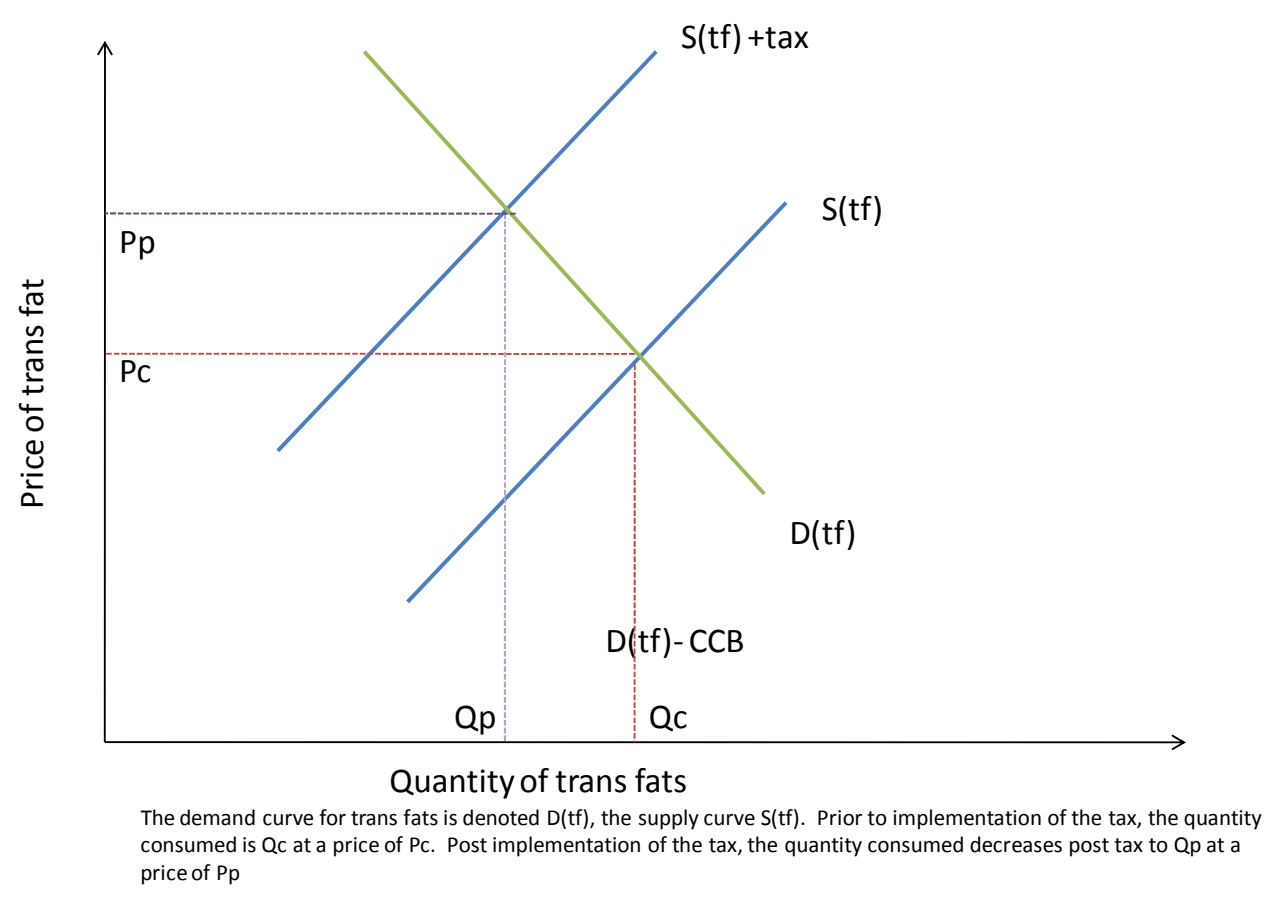

Studies have also shown that a tax on trans or saturated fats increases the consumption of sugar (World Health Organisation, 2008), an indirect substitute, linked to both obesity and, more specifically, Type II diabetes. Soft drinks, a complement to high trans and saturated fat content food, may see a slight decline in demand with an increase in the cost of trans and/or saturated fat, but not to the same extent as the total increase in sugar to make up the total calorific intake compensating for reduced trans and saturated fat consumption. Therefore any tax 
on trans on saturated fats would conceivably be needed to extend to encompass sugars as well.

If such a tax encompassing trans and saturated fats and sugars were to be implemented, what form should the tax take? One option would be a Pigovian type tax whereby a tax would be applied to the amount of trans, saturated fats and sugars in the product. The producer would then have an incentive to lower the amount of trans, saturated fats and sugars to an acceptable level as stipulated by the tax rate to increase demand for their product (as depicted in Figure 3).

A key issue here however, is how much tax is necessary to give the required result, largely governed by elasticity of demand. Secondly, lower income sections of the community would be paying a larger proportion of their income on this type of tax; such a tax would then be seen as regressive.

Unhealthy foods containing high concentrations of trans and saturated fats or sugars would tend to show a high elasticity of demand due to the availability of food alternatives, notwithstanding the argument that they may be especially addictive. Due to the popularity of fast foods with lower socio-economic sections of the community and the purchase of food taking up a higher percentage of monthly income than those of higher socio-economic groups, it is expected that the elasticity of demand would be greatest for this socio-economic group, whose demand would likely reduce once the tax was implemented. Impact on medium to high socioeconomic sections of the community would be impacted to a lesser extent due to the negative income elasticity of demand and thus a preference for "normal" or "superior" foods.

The tax would need to be legislated on the federal, not the state level to prevent the bulk buying of unhealthy foods at cheaper prices in other states. A federally legislated tax would stay the beginnings of a grey market for untaxed foods from non participating states in those states upholding the legislation of the tax. If such a 
tax were implemented, the revenues earned would be substantial. These revenues could then be channelled back into education programs and subsidies for healthy foods, in addition to funding health care for the obese, partially overcoming existing market failures.

To minimise the effects of imports of trans fats, saturated fats and sugars which may negate the effects of the Pigovian tax, a specific tariff for each of these food types commensurate with the federal Pigovian tax should be implemented. Whilst this would result in a deadweight loss to the domestic economy from reduced efficiency of supply and reduced demand (protective and consumption effects), the ultimate effect will achieve the reduction in demand for both local and imported goods of this nature (see Figure 4).

FIGURE 4: MARKET IMPLCATIONS OF IMPOSING A SPECIFIC TARIFF

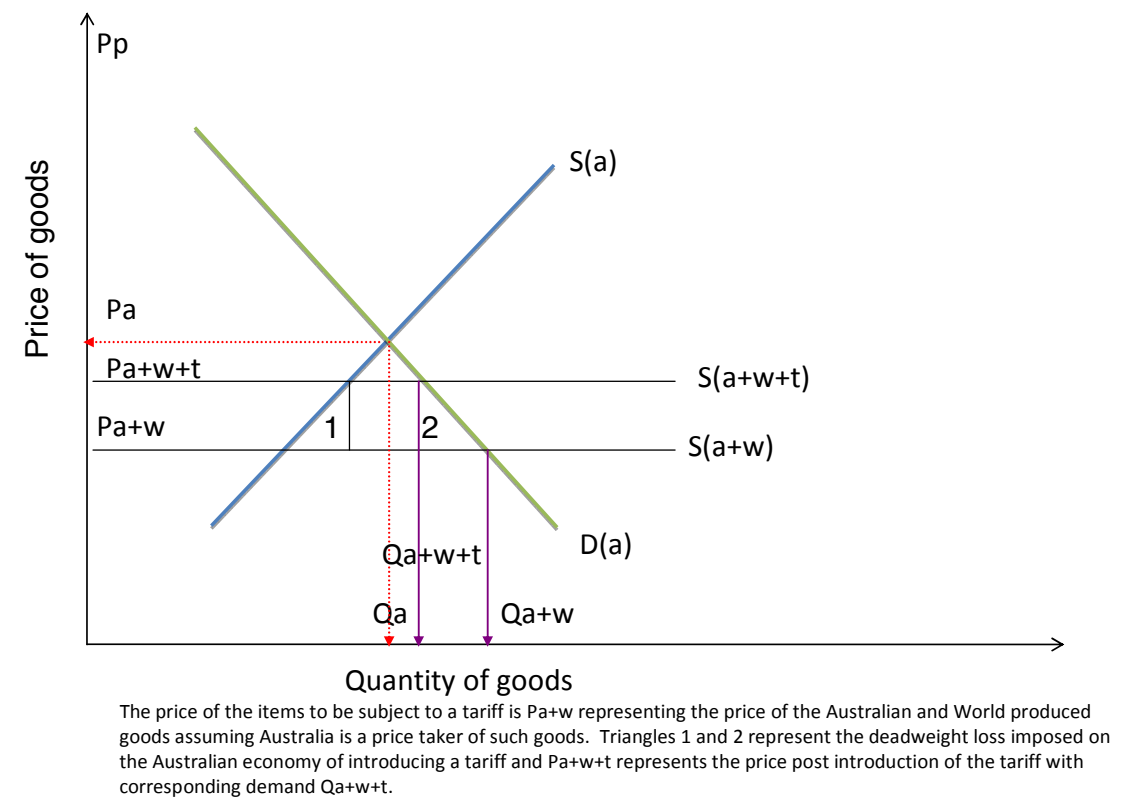


Healthy foods, such as fruit and vegetables, are GST exempt; however a rebate or subsidy for purchases of healthy food may provide an additional incentive for increased demand. Such an incentive alone may not necessarily reduce short-run consumption of saturated fats or unhealthy foods, for which consumers may have already established a preference. It may, however, act as an incentive to consumers without an already prior established preference, particularly when coupled with heavily taxed unhealthy products (see Figure 5).

\section{FIGURE 5: CROSS-EASTICITY OF DEMAND FOR HEALTHY FOODS}

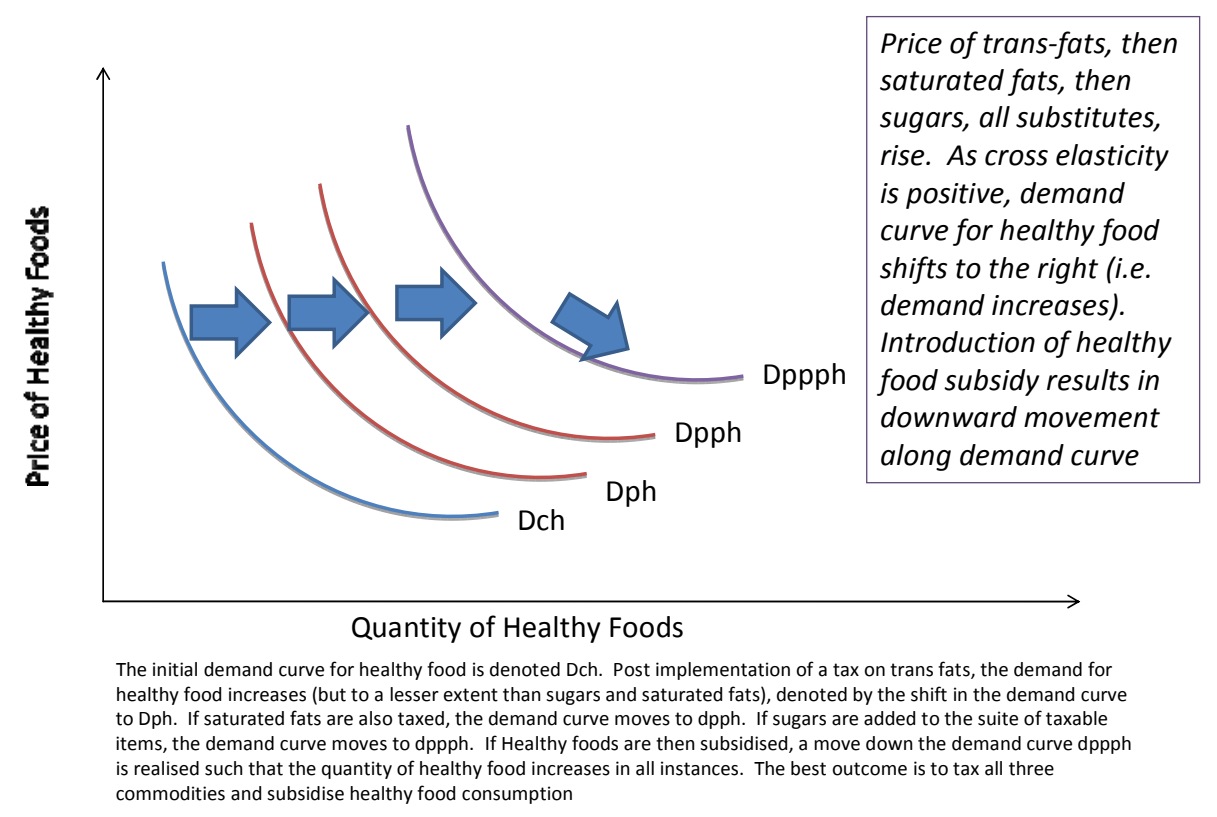

A ban on the advertising of unhealthy products may further reduce demand as market awareness increases. An advertising ban is likely to have more of an impact 
in the longer term; however in the short term given the extensive marketing of such products in the current environment the effect is likely to be more muted. It is thus unlikely to achieve neither the immediate impact required, nor the desired extensive long-term reduction in obesity as a solitary measure.

No option alone would achieve the desired outcome of reducing the consumption of unhealthy foods. A combination of approaches is preferable. Such a combination would impose a tax and specific import tariff on trans, saturated fats and sugars which will subsidise the consumption of healthy foods, exercise (such as in the form of gym membership subsidies), and an education program encompassing the benefits of exercise and healthy eating in addition to the treatment of obesity and obesity related illnesses. The introduction of said taxes are likely to have the greatest impact on the lower socio-economic sections of the community due to their regressive nature since it is this section of society that has a higher prevalence of obesity and related illnesses, thus lessening existing market failures. Advertising bans on unhealthy foods would also contribute to a cumulative beneficial outcome, the combined approach having the greatest potential to reduce the incidence of obesity, thus reducing the total cost of obesity to the community.

\section{References}

- Australian Bureau of Statistics (2008), Catalogue 1301.0 http://www.abs.gov.au/AUSSTATS/ABS@.NSF/7d12b0f6763c78caca257061001cc5 88/2710da48a1baf1a9ca2573d200107562! OpenDocument (Last accessed May 25 ${ }^{\text {th }}$, 2008)

- Australian Broadcasting Corporation (2005), "The effects of trans fat", Reporter: Mark Bannerman , Broadcast: 15/12/2005 http://www.abc.net.au/7.30/content/2005/s1532155.htm (last accessed June 1, 2008)

- The Economist (Nov. $\left.9^{\text {th }}, 2006\right)$ 